\title{
Przełamując spojrzenie Orfeusza Praca (anty)archiwalna Brachy L. Ettinger
}

\section{Diverting Orpheus's Gaze. (Anti-)archival Work of Bracha L. Ettinger}

Abstract: Bracha L. Ettinger's artistic series, Eurydice, is grounded upon a historical photograph from the liquidation of the Mizoch ghetto on 14 October 1942, depicting naked women and children waiting to be executed. The artist treats this picture as a basis of her artworks and covers it with layers of paint. It is, however, difficult to identify this art as archival. By means of her artistic procedures, Ettinger endeavours to free her paintings from the bounds of representation; what she does is - as I claim - (anti-)archival work. This article aims at studying the relation between Ettinger's oeuvre and the photographic archive. First, I try to point out the insufficiency of the archive and to identify Ettingerian attempts to work it through. Second, I discuss the notion of the gaze in the matrixial psychoanalysis. Just as the look of Orpheus sends Eurydice back to the Underworld, the spectator's gaze may kill the women from Mizoch again; this is the impasse Ettinger strives to break.

Keywords: Bracha L. Ettinger, matrixial theory, Eurydice, Orpheus, archive, photography and the Holocaust, the Mizoch ghetto

Orfeusz spogląda. Eurydyka ukazuje się jego oczom, za wcześnie. Za późno! Kobieta gaśnie, w połowie drogi ku powierzchni, wpót-pojawiając się z Orfeuszem: to zniknięcie we wspólpowstawaniu ${ }^{1}$.

Brian Massumi

Zdjęcie numer 17877: "Nagie kobiety pochodzenia żydowskiego, z których część trzyma w rękach niemowlęta, stoją w rzędzie, czekając na egzekucję z rąk Sipo i SD, wspieranych przez ukraińskie oddziały pomocnicze”2. Zwięzły opis dostępny na stronie United States Holocaust Memorial Museum w Waszyngtonie

1. Brian Massumi, "Afterword. Painting: The Voice of the Grain", w: Bracha L. Ettinger, The Matrixial Borderspace, red. Brian Massumi (Minneapolis-London: University of Minnesota Press, 2006), 207. Jeśli nie zaznaczono inaczej w tekście, cytaty z języka angielskiego w przekładzie autorki.

2. Zdjęcie jest dostępne w internetowych archiwach United States Holocaust Memorial Museum w Waszyngtonie; na stronie muzeum można również odnaleźć dodatkowe informacje 
przybliża zawartość jednej z kanonicznych fotografii Zagłady, dokumentującej likwidację getta w Mizoczu dnia 14 października 1942 roku. Obraz ten wydaje się łączyć różne obszary działalności Brachy L. Ettinger - psychoanalityczki, twórczyni teorii macierzy, artystki - ale to w sztuce wyłania się na pierwszy plan. Bracha L. Ettinger skanuje zdjęcie, czasem kilkukrotnie, zatrzymując kopiarkę w trakcie pracy, po czym nakłada na powstały "widmowy" ślad warstwy farby3. Jak jednak zamierzam udowodnić, nie możemy określić jej dzieł mianem archiwalnych. W końcu celem artystki, będącej córką polskich Żydów ocalałych z Holokaustu, nie jest reprezentacja okrucieństwa, którego ofiarami były bohaterki obrazu. Jej sztuka stara się uniknąć diagnozy Susan Sontag, wedle której “[e]tyczna zawartość zdjęć jest nietrwała", a ogromna masa obrazów przedstawiających okropności jedynie widza znieczula. Ettinger nie próbuje niczego widzowi przedstawić. Zamiast tego wykonuje ona pracę artystyczną (artwork). Wykorzystuje tym samym dwuznaczność angielskiego terminu, wpisując się w tradycję psychoanalizy - nawiązuje do takich pojęć jak przepracowanie (working through), praca marzenia sennego (dreamwork), praca żałoby (work of mourning) - i sięga do twórczego, afektywnego potencjału treści nieświadomych, czy to po stronie widza, czy też artysty. Podstawą tej pracy staje się odejście od holistycznego, odindywidualizowanego ujęcia. Ettinger kadruje oryginalną fotografię, a w obrazach wykorzystuje jej różne fragmenty, zwracając uwagę na pomniejsze relacje, dla których w perspektywie całościowej trudno znaleźć miejsce; płótna w serii malarskiej Eurydice zamieszkują więc: matka obejmująca niemowlę, kobieta w ciąży, dziewczynka tuląca się do nóg innej kobiety, kobieta patrząca w dal, jakby szukająca czyjegoś wzroku, w końcu kobiety w (u)ścisku, będącym ostatnim doświadczeniem bliskości przed śmiercią. Za pomocą takich zbliżeń artystka, jak twierdzę, wykonuje również pracę (anty) archiwalna; mianowicie, odrzucając masowy charakter fotograficznego oryginału, Ettinger niejako skłania nas ku intymności - ku bliskiemu spotkaniu, którego nie da się uchwycić w opisie zorientowanym na fakt historyczny.

Szkic ten stanowi próbę analizy twórczości Brachy L. Ettinger pod kątem jej związków z archiwum fotograficznym. Postaram się wykazać, że dla Ettinger

na temat okoliczności powstania zdjęcia. Numer referencyjny zdjęcia: \#17877; https://collections. ushmm.org/search/catalog/pa1065461 (28.12.2019). Opis i tytuł zdjęcia w przekładzie autorki.

3. Dogłębne omówienie twórczości artystycznej Ettinger oferuje Anna Chromik, kuratorka pierwszej indywidualnej wystawy Brachy L. Ettinger w Polsce (Eurydyka - Pieta, Muzeum Śląskie, Katowice, 8.07.-2.09.2017), w tekście: “Dotyk, rytm i współświadczenie. O afektywnym potencjale materialności i taktylności w twórczości Brachy Ettinger”, Widok. Teorie i Praktyki Kultury Wizualnej, nr 23, 2019, http://www.pismowidok.org/pl/archiwum/2019/23-sila-kobiet/ dotyk-rytm-i-wspolswiadczenie (20.12.2019).

4. Susan Sontag, "W platońskiej jaskini”, w: O fotografii, przeł. Sławomir Magala (Warszawa: Wydawnictwa Artystyczne i Filmowe, 1986), 24. 
archiwum - rozumiane jako medium próbujące utrwalić wydarzenie historyczne pod postacią stabilnej reprezentacji - okazuje się formą niewystarczającą, jak również zidentyfikować sposoby przepracowania materiału archiwalnego, z którego przecież sztuka Ettinger wyrasta. Ponadto, włączając w dyskusję elementy teorii macierzy, poruszę kwestię spojrzenia widza, które - niczym wzrok Orfeusza, skazujący Eurydykę z powrotem na krainę umarłych - może ponownie uśmiercić kobiety z Mizocza. Spojrzenia, które Ettinger usiłuje przełamać.

Wzrok Orfeusza jest tym, co równocześnie zsyła Eurydykę w niebyt oraz potwierdza - na ułamek sekundy - jej istnienie. Nazywając swoją serię malarską Eurydice, Ettinger oddaje głos tej granicznej figurze. W micie o jej istnieniu decyduje umowa między Hadesem i Orfeuszem; Orfeusz może wyprowadzić Eurydykę z zaświatów, ale nie wolno mu na nią spojrzeć. Warunek - z pozoru prosty do spełnienia - okazuje się próbą zaufania, którego Orfeuszowi ma ostatecznie zabraknąć. Gdy ten odwraca się, by sprawdzić, czy ukochana za nim podąża, Eurydyka jawi się przed jego oczami, by zaraz zniknąć na zawsze. Jego spojrzenie chwyta ją w paradoksalnej nie-skończoności: w zawieszeniu między obecnością a nieobecnością, życiem a śmiercią. W końcu, cytując Judith Butler, Eurydyka "[i]dzie w naszą stronę, zanika oddalając się od nas, i obie te czynności są naraz prawdziwe" ". Co więcej, wiedza o niej skazana jest na swoistą nie-pełność - gdy Orfeusz spogląda, kobieta jest widoczna, ale wizja już się rozmywa. Niedookreślenie, zanikanie, zawieszenie - te cechy konotują pracę artystyczną Ettinger. Archiwalna fotografia-baza istnieje, ale na płótnach Ettinger przestaje być nośnikiem historycznej informacji - pojawia się na nich fragmentarycznie, a czasem widz traci nawet pewność, czy to zdjęcie w ogóle zostało nałożone na płótno. Kobiety z Mizocza to się pojawiają, to znów uciekają przed spojrzeniem obserwujących, nigdy nie dochodząc do stanu pełnej widzialności z dokumentu. Ich status pozostaje więc zawieszony między przyjętymi podziałami: na obrazach żyją, a przecież już umarły; pojawiają się, choć nie w pełni i nie (na) zawsze; są teraz, jednak ich przeszłość i przyszłość już się dokonały. Jak się okazuje, zawieszenie to wynika $\mathrm{z}$ działań nie tylko artystki, ale i widzów, którym przyszło podążać za Eurydykami.

Motywy zawieszenia oraz zaburzania dychotomii w micie o Eurydyce i Orfeuszu stanowią również istotny punkt odniesienia w myśli psychoanalitycznej Brachy L. Ettinger. Już samo pojęcie macierzy (matrix), ze względu na odwołanie

5. Judith Butler, “Foreword: Bracha's Eurydice”, w: Bracha L. Ettinger, The Matrixial Borderspace..., viii. 
do ciąży i macierzyństwa, ma odznaczać się zawieszeniem - zdawałoby się - nienaruszalnej opozycji między podmiotem a Innym. Ettinger stwierdza:

Od chwili, gdy mówimy o podmiocie, możemy również mówić o powiększonej podmiotowości. W Macierzy ma miejsce spotkanie między wspól-powstającym ja a nieznanym nie-ja. Żadne z nich nie asymiluje lub odrzuca tego drugiego, a ich energia nie opiera się ani na fuzji, ani na odpychaniu [repulsion], ale na nieustannym regulowaniu odległości, nieustannym negocjowaniu oddzielności i oddalenia w ramach wspólnoty i bliskości ${ }^{6}$.

Macierz to element znaczący nie-fallicznej, nie-edypalnej, zawsze negocjowalnej różnicy-w-bliskości, ale także przestrzeń pierwotnego spotkania - między matką a dzieckiem - kształtującego naszą podmiotowość przed i poza serią cięć, omawianych szeroko w psychoanalizie freudowsko-lacanowskiej. Podczas tego spotkania - uniwersalnego wydarzenia zarówno dla kobiet, jak i dla mężczyzn ${ }^{7}$ może nastąpić transfer śladów wiedzy, a zatem również traum i cierpienia ${ }^{8}$. W tym właśnie miejscu teoria zazębia się z postpamięciowymi doświadczeniami Ettinger przynależącej do drugiego pokolenia po Holokauście - rodzice Ettinger byli polskimi Żydami, którym podczas wojny udało się po wielu trudach uciec do Palestyny.

Mit o Orfeuszu i Eurydyce staje się dla Ettinger także przyczynkiem do refleksji nad doświadczeniem sztuki. Jednym z podstawowych terminów w tym kontekście jest spojrzenie, polegające na swoistym zawieszeniu w danym spotkaniu-wydarzeniu. Macierzowego spojrzenia nie należy mylić z Lacanowskim fascinum: obiektem małe a, które Ettinger odczytuje jako "produkt kastracji" oraz "nieświadomy element obrazu, który zatrzymuje i zamraża życie" . Ettinger stwierdza, że sfera macierzy zezwala na pojawienie się fascinance: "afektu estetycznego działającego w zawieszeniu i hojnym przedłużeniu trwania spotkania-wydarzenia"10. Zamiast

6. Bracha L. Ettinger, "Woman-Other-Thing: A Matrixial Touch", w: Matrix - Borderlines, Museum of Modern Art, Oxford 1993, 12, cyt. za: Griselda Pollock, "Introduction. Femininity: Aporia or Sexual Difference?", w: The Matrixial Borderspace..., 14.

7. Griselda Pollock pisze wprost: "Ta teoria nie jest tylko o kobietach dla kobiet, ale dla nas wszystkich, ponieważ wszyscy jesteśmy zrodzeni z kobiety". Pollock, "Introduction. Femininity...", 29.

8. Dla szerszego omówienia teorii macierzy w kontekście psychoanalizy i studiów nad traumą, zob. Anna Kisiel, "Uraz - bliskość - nie-pamięć. Psychoanalityczny dyskurs traumy od Freuda do Ettinger”, Narracje o Zagładzie, nr 2, 2016, 115-132.

9. Bracha L. Ettinger, "Fascinance and the Girl-to-m/Other Matrixial Feminine Difference", w: Psychoanalysis and the Image: Transdisciplinary Perspectives, red. Griselda Pollock (Oxford: Blackwell Publishing Ltd., 2006), 60.

10. Bracha L. Ettinger, "Fragilization and Resistance", Studies in the Maternal, t. 1, nr 2, 2009, 3, http://www.mamsie.bbk.ac.uk/back_issues/issue_two/documents/Brachal.pdf (16.04.2013). W artykule "Nie do powiedzenia. O głosie u Lacana, Ettinger i Woodman," Er(r)go. Teoria - Literatura - Kultura, nr 33 (2/2016), 81-91, omawiam kategorię głosu; jest on odczytywany przez 
zamrażać - czy wręcz unicestwiać - życie, fascinance sprawia, że macierzowa sfera upodmiotowienia rozciąga się w czasie, umożliwiając tym samym dłuższą wzajemną transformację uczestników spotkania. Istnieje, co prawda, niebezpieczeństwo, że fascinance przekształci się w swój falliczny odpowiednik, ale rolą współczucia, kruchości i otwartości na Innego jest zapobieganie temu zagrożeniu. Niemal bezgraniczne zaangażowanie w obserwowaną scenę pozwala zatem na wytworzenie się nici połączenia między mną a Innym, w ramach którego burzone są dychotomie takie jak “ja” / "nie-ja”, obecność / nieobecność czy teraźniejszość / przeszłość.

To właśnie w afektywnym połączeniu - a nie uzyskaniu i uprawomocnieniu historycznego faktu - Ettinger dostrzega największą obietnicę spotkania widza z obrazem. W akcie gościnności, płótno Eurydice, No. 5 (1992-1994), tu reprodukowane na stronie $103^{11}$, przejmuje fragment zdjęcia, na którym jesteśmy w stanie rozpoznać kobiety z Mizocza, ale trudno zaklasyfikować ten obraz jako sztukę archiwalną. Powiększeniu i rozmyciu ulegają ciała kobiet, a także ich twarze, które artystka zapełnia za pomocą plam i cieni. Wszelkie próby uzyskania wiedzy - chociażby na temat wyrazu twarzy kobiety spoglądającej w dal - będą bazowały właśnie na ingerencji Ettinger. Samozwańczy podtytuł obrazu - napis vivante/ morte znajdujący się w jego górnej części - przypomina nam, że każda z tych kobiet skazana jest na los Eurydyki: "cienia istniejącego między życiem a śmiercią, figury straty i miłości”12. Jednak nie tylko elementy dzieła są zawieszone. W ramach Ettingeriańskiego ujęcia spojrzenia, zawieszeniu może ulec również pozycja widza. Schwytany w fascinance, zaangażowany podmiot-widz ma szansę doświadczyć pozajęzykowego spotkania z Innymi, którzy - choć anonimowi - nagle stają się niezwykle bliscy: czy to z kobietą zwróconą w stronę aparatu, czy to z dziewczynką, czy to z matką obejmującą niemowlę. Mimo że ich historie wykraczają poza poznawcze możliwości widza, któremu przekazane są jedynie ślady i fragmenty, w spotkaniu tym - niczym w Barthes'owskim doświadczeniu punctum - dokonuje się zmiana, która według Ettinger jest cenniejsza niż często zdepersonalizowany fakt.

Ettinger sprzeciwia się kilku aspektom definiującym klasycznie rozumiane archiwum, stwierdzając, że w kontekście Szoa jego formuła nie wystarcza.

Jacques’a Lacana również jako objet petit $a$, podczas gdy u Ettinger głos zostaje uznany za link a obiekt-połączenie.

11. Ten obraz jest przeze mnie przytaczany w nieco innym kontekście w artykule "Touching Trauma: On the Artistic Gesture of Bracha L. Ettinger” (Narracje o Zagładzie, nr 4, 2018, 138-162), stanowiącym przegląd serii Eurydice, w którym poruszam, między innymi, kwestie dotyku i bliskości, gestu artystycznego Ettinger, traum(y) w jej sztuce i teorii, zawieszenia, zaufania, pamięci oraz seryjności.

12. Christine Buci-Glucksmann, "Eurydice's Becoming-world", w: Art as Compassion: Bracha L. Ettinger, red. Catherine de Zegher i Griselda Pollock (Brussels: ASA Publishers, 2012), 69. 
U Barbie Zelizer czytamy, że "wizualizacja Holokaustu jest tak dominująca, że stała się integralną częścią rozumienia i pamiętania okrucieństw drugiej wojny światowej”'13. Prymat reprezentacji, oparty w popularnej świadomości przede wszystkim na kilkunastu najsławniejszych kadrach, nie dostarcza już jednak ładunku afektywnego. Aleksandra Szczepan komentuje to zjawisko, opierając się na pojęciu "pamięciowych wskazówek" ${ }^{14}$ proponowanych przez Zelizer. "Działają [one] na zasadzie krótkiego spięcia, skokowego przypomnienia, które odsyła do ogólnikowej wiedzy, nie znajdując żadnego osadzenia w formie afektywnej czy etycznej relacji"15. Tym samym z jednej strony można zaobserwować redukcję do kilkunastu fotograficznych ujęć kształtujących pamięć i świadomość całego społeczeństwa, a z drugiej strony - bombardowanie masami obrazów, czego przykładem jest Państwowe Muzeum Auschwitz-Birkenau w Oświęcimiu. Obie te tendencje ostatecznie prowadzą do tego samego skutku - znieczulenia, by posłużyć się kategorią Sontag ${ }^{16}$. Sztuka Ettinger wydaje się umykać czystej reprezentacji. Griselda Pollock stwierdza, że Ettinger odchodzi od treści, zwracając uwagę widza na sam gest - malarski i etyczny ${ }^{17}$. Co więcej, sztuka ta sprzeciwia się znieczuleniu, mimo że obrazy Ettinger zwykle "przybywają tłumnie”18, jak określa to Brian Massumi, mając na myśli zarówno ich dużą liczbę, jak i tłoczące się kobiety, stanowiące podstawę większości "Eurydyk". W pracy nad materiałem $\mathrm{z}$ archiwum Szoa Ettinger odcina się tym samym od tego, co Ernst van Alphen identyfikuje jako "puryzm"19 archiwalny - poszukiwanie czystej reprezentacji pozbawionej śladów narracji czy interpretacji. Tę postawę van Alphen uważa za niebezpieczną:

[T]aka strategia powtarza jedynie gest oprawców, mistrzów biurokratycznej czystości, Nazistów. [...] [K]iedy uprzywilejowuje się archiwum (jako sposób przedstawienia danych) i pozbawia się prawa do interpretacji i wyobraźni, czystość klasyfikacji i wyliczania faktów

13. Barbie Zelizer, "Introduction: On Visualizing the Holocaust", w: Visual Culture and the Holocaust, red. Barbie Zelizer (London: Athlone Press, 2001), 1. Przekład za: Aleksandra Szczepan, "Krajobrazy postpamięci", Teksty Drugie, nr 1, 2014, 112-113.

14. Barbie Zelizer, Remembering to Forget. Holocaust Memory through the Camera's Eye (Chicago-London: University of Chicago Press, 1998), 188, 191.

15. Szczepan, "Krajobrazy postpamięci...”, 114.

16. Sontag, "W platońskiej jaskini...,", 24.

17. Griselda Pollock, "Introduction: Trauma and Artworking", w: After-affects / After-images. Trauma and Aesthetic Transformation in the Virtual Feminist Museum (Manchester-New York: Manchester University Press, 2013), 3.

18. Massumi, "Afterword...", 204.

19. Zob. Ernst van Alphen w rozmowie z Romą Sendyką i Katarzyną Bojarską, "Afekt, trauma i rozumienie: Sztuka ponad granicami”, Tekstry Drugie, nr 4, 2012, 210. 


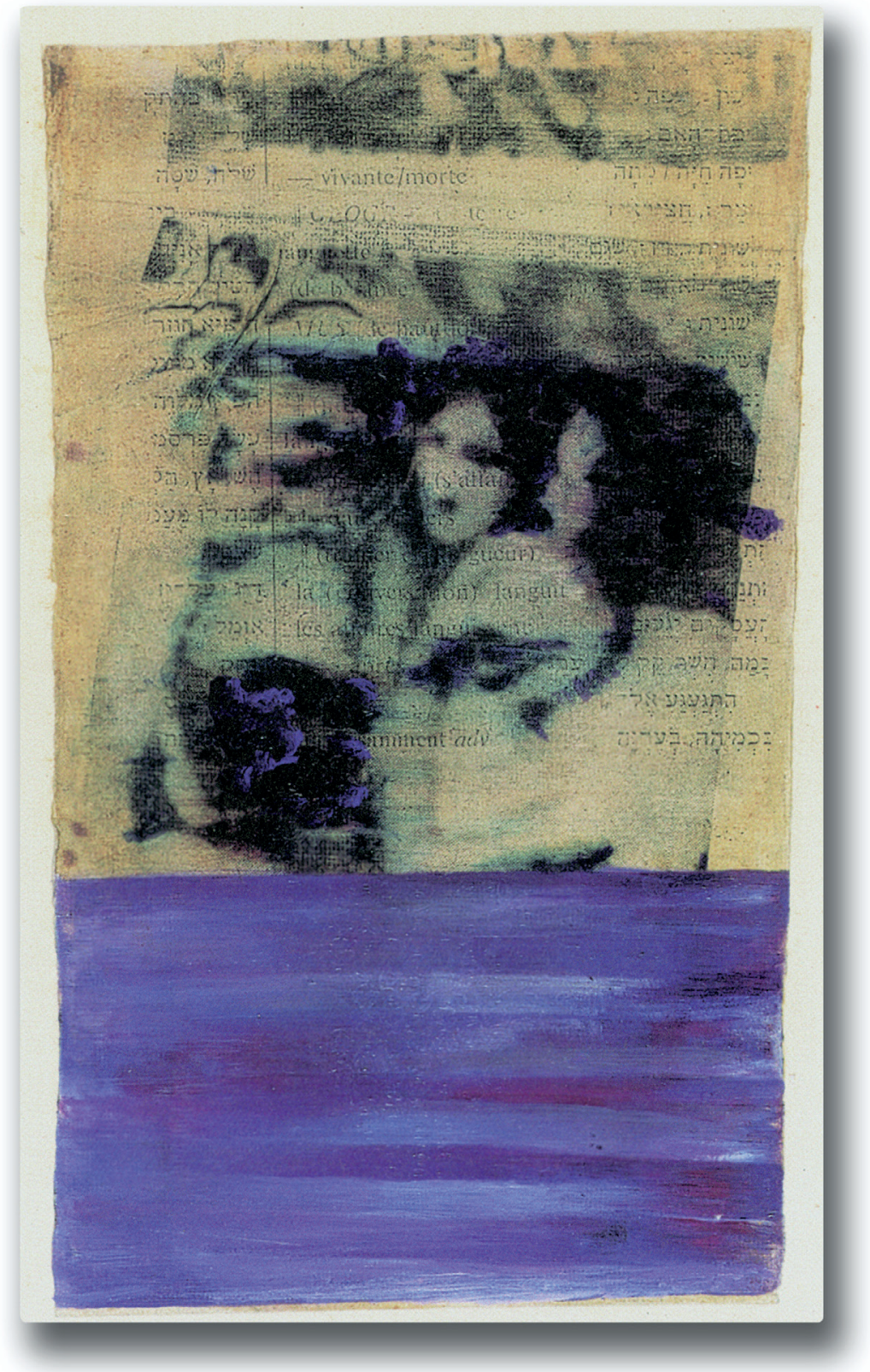

Fot. 1. Bracha L. Ettinger, Eurydice No. 5, 1992-1994 olej, kserokopia z pigmentem i popiołem na papierze naklejonym na płótno, $47 \times 27 \mathrm{~cm}$. Collection Israel Museum, Jerusalem; reprodukcja dzięki uprzejmości Artystki (oil, xerography with photocopic pigment and ashes on paper mounted on canvas. Collection Israel Museum, Jerusalem. Copyright courtesy of the Artist). 
może zaprowadzić nas do piekła systematycznego zniszczenia. Obozy koncentracyjne to w pewnym sensie ogromne $\operatorname{archiwa}^{20}$.

Zamiast fetyszyzować materiał archiwalny, Ettinger pracuje na nim, robiąc to w sposób bliski postulatom Jill Bennett. Uściślając, Ettinger wykorzystuje zmysł wzroku, by dotknąć "pamięci cielesnej" widza - by wzbudzić afektywną odpowiedź, zanim widz nałoży na obserwowane zdarzenie nabyte ramy narracyjne czy moralne ${ }^{21}$. Choć więc wiedza na temat bazowego zdjęcia może być pomocna w odczytaniu i kontekstualizacji serii Eurydice, Ettinger swoim gestem artystycznym pragnie odwołać się do macierzowego połączenia inspirowanego spotkaniem prenatalnym, w którym strzępy wiedzy - choć niepoznawalnej - są przekazywane cieleśnie i afektywnie, jeszcze przed wytworzeniem binarnego systemu językowego.

Fiolety, czerwienie i czernie pokrywają płótno i zdjęcie na obrazie Eurydice, No. 12 (1994-1996). Możemy się domyślić, że w ramach obrazu znajduje się powiększony fragment zdjęcia kobiet z Mizocza, ale zidentyfikowanie ich staje się trudne. Kontury ciał są niemal niewidoczne, podobnie jak twarze, na których nie znajdziemy już śladu strachu czy innych emocji. Fiolet staje się tu odzieniem kobiet, które okrywa je i ukrywa przed spojrzeniami uruchamiającymi Zelizerowskie "pamięciowe wskazówki". "Eurydyki" to się pojawiają, to znikają. Fragmenty zdjęcia wyłaniają się na powierzchnię, ale nie stają się w pełni widzialne. To, co na tym obrazie wydaje się najważniejsze, to intensywność koloru, doświadczenie bliskości oraz zaufanie cecha, której najwyraźniej brakło Orfeuszowi. By użyć słów Massumiego: “Orfeusz spogląda. Eurydyka ukazuje się jego oczom, za wcześnie. Za późno! Kobieta gaśnie, w połowie drogi ku powierzchni, wpół-pojawiając się z Orfeuszem: to zniknięcie we współpowstawaniu"22. Spojrzenie Orfeusza przyniosło kobiecie powtórną śmierć, równocześnie afirmując jej istnienie. Ettinger pragnie, byśmy spotkali się $\mathrm{z}$ Eurydyką $\mathrm{w}$ tym granicznym ułamku sekundy, ale by zdarzyło się to również na jej zasadach, w przestrzeni opartej na wzajemności i bliskości.

Dla Brachy L. Ettinger etyczna wartość spotkania z Eurydyką ma znaczenie priorytetowe, a jej postulaty w tym kontekście zbliżają teorię macierzy do myśli Emmanuela Lévinasa ${ }^{23}$. Dla Lévinasa podmiotowość jest $z m y s ł o w o s ́ c i q{ }^{24}$ :

20. Alphen, “Afekt, trauma i rozumienie...", 210.

21. Jill Bennett, Empathic Vision. Affect, Trauma, and Contemporary Art (Stanford: Stanford University Press, 2005), 36.

22. Massumi, "Afterword...", 207.

23. Dla bardziej szczegółowego omówienia związków między teoriami Brachy L. Ettinger i Emmanuela Lévinasa w kontekście kobiecego ciała, zob. Anna Kisiel, "Aesth/ethical Bodies: Bracha Ettinger's Eurydices and the Encounter with the Other's History”, w: The Body in History, Culture, and the Arts, red. Justyna Jajszczok i Aleksandra Musiał (New York-London: Routledge 2019), 149-160.

24. Używam pojęcia zmysłowości za przekładem Małgorzaty Kowalskiej. 


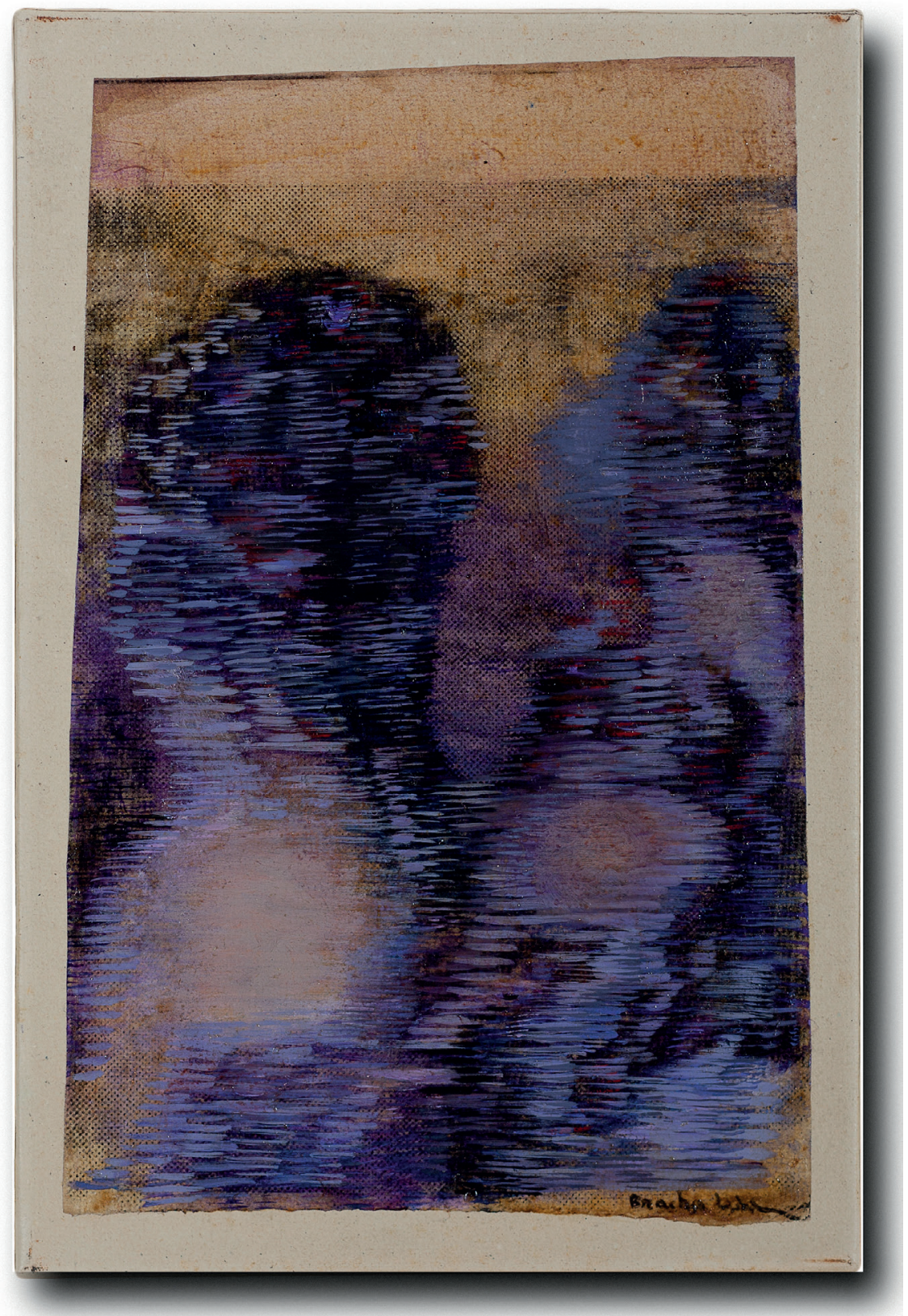

Fot. 2. Bracha L. Ettinger, Eurydice No. 12, 1994-1996, olej i media mieszane na papierze naklejonym na płótno, $38,5 \times 24,5 \mathrm{~cm}$. Reprodukcja dzięki uprzejmości Artystki (oil and mixed media on paper mounted on canvas. Copyright courtesy of the Artist). 
“otwarciem się na innych, podatnością na zranienie i odpowiedzialnością w bliskości innych, znaczeniem jeden-za-drugiego [...]"25. Przyczynkiem do twierdzeń na temat etycznego spotkania $z$ Innym staje się natomiast matczyne ciało ${ }^{26}$. To, co silnie łączy dwa omawiane systemy, to swoista otwartość na to, co Inny ze sobą niesie, a zatem liczenie się z możliwością doznania bólu. U Ettinger wyraźną manifestację tej cechy odnajdziemy w pojęciu samorozkruszenia (self-fragilisation), procesie prowadzącym do ekstremalnej bliskości między podmiotem a Innym, która to bliskość ma poważne konsekwencje. Ettinger pisze:

Samorozkruszanie się jest ryzykowne, ale i bolesne, ponieważ dociera się do współczucia-poza-empatią oraz współ-czucia/pasji [com-passion], często trudnych do zniesienia na poziomie jednostki szukającej mentalnego poczucia bezpieczeństwa i potrzebującej wycofania się w swoje nawyki ${ }^{27}$.

Z jednej strony ta procedura jest groźna, ponieważ jej warunkami są kruchość i podatność intensywne na tyle, że przesuwają granice naszej podmiotowości. Równocześnie, dzieje się tu rzecz odwrotna: owo zatarcie rozróżnienia na "ja" i "nie-ja" czyni nas kruchymi i podatnymi, a przez to - odsłoniętymi przed anonimowym Innym, bezbronnymi wobec krzywd, które może nam wyrządzić. Jednak to właśnie w samorozkruszeniu Ettinger dopatruje się potencjału etycznego. Działanie to ma pozwolić na współdzielenie afektywnych śladów informacji między podmiotami, a zatem na częściowe doświadczenie nieswoich traum, bólu, cierpienia czy upokorzenia. Jeśli poprzez samorozkruszenie otworzymy się na taką transmisję, zamiast nas przytłaczać, staje się ona uczłowieczająca: choć sprawia nam ból, równocześnie zmienia nas, a nawet - leczy ${ }^{28}$. To zaś może prowadzić do wytworzenia się podmiotowości-jako-spotkania (subjectivity-as-encounter) - instancji podmiotowości jeszcze sprzed momentu odcięcia, opartej na pierwotnym spotkaniu w ciele kobiety/stającej-się-matki ${ }^{29}$. Spotkanie to wymaga samorozkruszenia, by możliwe było stanięcie twarzą w twarz z Innym - nawet jeśli stawką okaże się własne bezpieczeństwo. W tym miejscu Ettinger ponownie wchodzi $\mathrm{w}$ dialog z Lévinasem - tym razem $\mathrm{z}$ postulowanym przez francuskiego

25. Emmanuel Lévinas, Inaczej niż być lub ponad istotą, przeł. Piotr Mrówczyński (Warszawa: Fundacja Aletheia, 2000), 130.

26. Zob. Lévinas, Inaczej niż być..., 127.

27. Ettinger, "Fragilization and Resistance...", 9.

28. Zob. Bracha L. Ettinger, "Trans-subjective Transferential Borderspace”, w: A Shock to Thought: Expression after Deleuze and Guattari, red. Brian Massumi (London-New York: Routledge, 2002), 236.

29. Dla szerszego omówienia podmiotowości-jako-spotkania i sprzeciwu wobec esencjalistycznym odczytaniom tego pojęcia, zob. Bracha L. Ettinger, "Weaving a Woman Artist with-in the Matrixial Encounter-Event”, w: The Matrixial Borderspace..., 179-184. 
filozofa terminem twarzy Innego. Jest ona opisana jako naga podczas spotkania z podmiotem ${ }^{30}$, "odsłonięta, zagrożona, jakby zapraszała nas do aktu przemocy. Równocześnie, to twarz zabrania nam zabić"31. Pomimo imperatywu "Nie zabijaj", twarz Innego okazuje się bezbronna wobec uprzedmiotowienia i agresji. U Ettinger ten model zostaje niejako odwrócony. W ramach podmiotowości-jako-spotkania, to "ja" jest bezbronne wobec Innego, to "ja" Innemu się poddaje w swej kruchości, w końcu to “ja” godzi się na potencjalne niebezpieczeństwa.

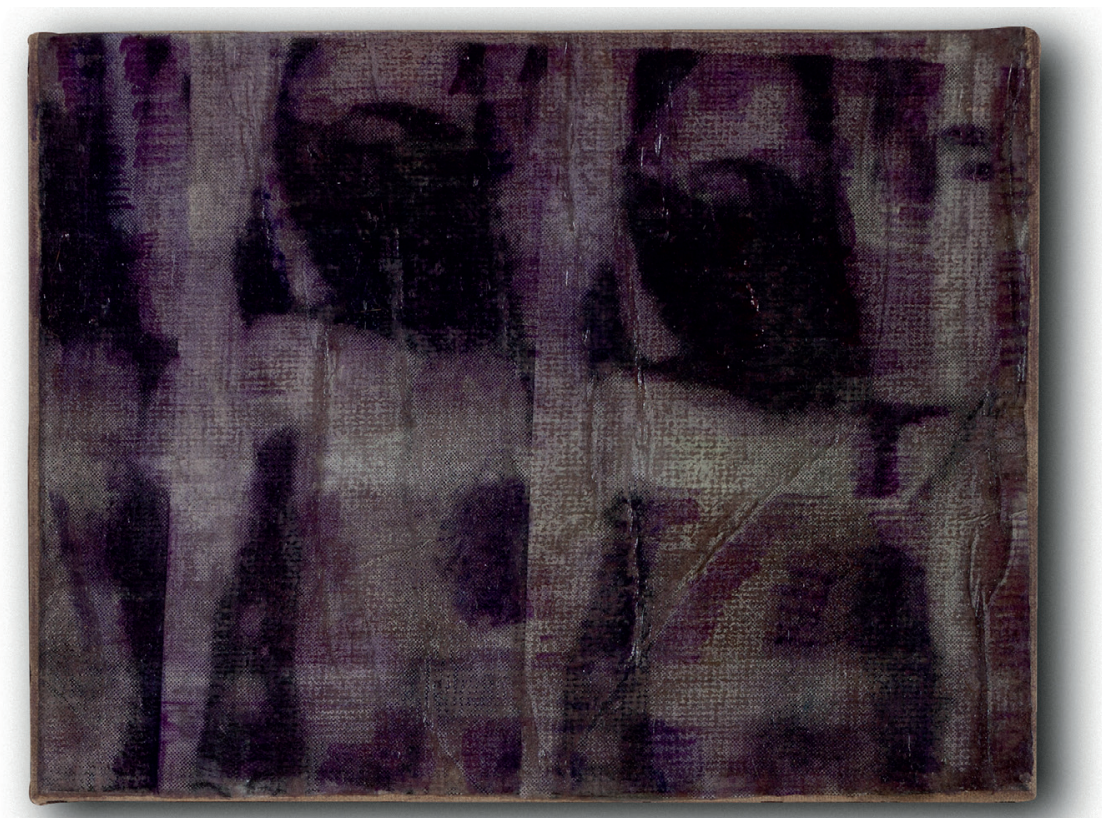

Fot. 3. Bracha L. Ettinger, Eurydice No. 38, 2001, olej, kserokopia z pigmentem i popiołem na papierze naklejonym na płótno, 21,6 ×28,2 cm. Reprodukcja dzięki uprzejmości Artystki (oil, xerography, photocopic pigment and ashes on paper mounted on canvas. Copyright courtesy of the Artist).

Spotkanie z Eurydice, No. 38 (2001) jest niewątpliwie wydarzeniem, które rozkrusza. Musimy stawić czoła dziewczynce z Mizocza, nagiej, upokorzonej i bezbronnej. Przestraszona tuli się do jakiejś kobiety - być może własnej matki. Ciało dziewczynki - powielone na płótnie około dwóch i pół razy - zdaje się postulować "Nie zabijaj", ale wiemy, że za kilka minut czy sekund, ten imperatyw

30. Emmanuel Lévinas, Całość i nieskończoność. Esej o zewnętrzności, przeł. Małgorzata Kowalska, przekład przejrzał Jacek Migasiński (Warszawa: Wydawnictwo Naukowe PWN, 1998), 233-235.

31. Emmanuel Lévinas, Ethics and Infinity. Conversations with Philippe Nemo, przeł. Richard A. Cohen (Pittsburgh: Duquesne University Press, 1995), 86. 
utraci rację bytu. Ponownie obserwujemy tu zawieszenie - jest to moment strachu i pociechy, miłości, która ostatecznie pokona zbliżającą się śmierć. Gest przytulenia niesie w sobie przywiązanie i czułość pomimo okropieństwa, w którym kobiecie i dziewczynce przyszło uczestniczyć. Jako widzowie zderzamy się z tym zaburzonym porządkiem "straty i miłości", a naszym obowiązkiem staje się afektywna odpowiedź - czy Lévinasowska odpowiedź-alność - oraz niezgoda na spojrzenie Orfeusza, zabijające dziewczynkę po raz kolejny.

Można pokusić się o stwierdzenie, że Ettinger w swojej sztuce przepracowuje archiwum Holokaustu, a jej gest malarski jest w zasadzie Freudowskim fort/da, gdzie zdjęcie kobiet staje się szpulką, raz po raz odrzucaną i przyciąganą ponownie. Teoretyczne refleksje Ettinger poszerzają jednak wymiar tych obrazów. Nigdy nieukończone, dzieła te zapraszają nas do interakcji w fascinance i do podążania za kobietami z Mizocza do granic widzialności - do śladów traumatycznego zdarzenia nienależących do nas, możliwych do uchwycenia dzięki samorozkruszeniu i otwartości na Innego. Dla Ettinger archiwum samo w sobie nie spełnia tych założeń, stawiając nacisk na fakt oraz jego reprezentację, która często prowadzi do przyzwyczajenia widza do obserwowanych okrucieństw. Artystka i psychoanalityczka wykonuje zatem pracę nad materiałem archiwalnym, by przełamać impas spojrzenia Orfeusza.

Chciałabym gorąco podziękować Brasze L. Ettinger zarówno za zgodę na opublikowanie reprodukcji obrazów, jak i za naszą rozmowę podczas konferencji Vulnerabilities w Katowicach w 2017 roku, która zainspirowała mnie do napisania tego artykułu. 


\section{Bibliografia}

Alphen, Ernst van w rozmowie z Romą Sendyką i Katarzyną Bojarską. "Afekt, trauma i rozumienie: Sztuka ponad granicami”. Teksty Drugie, nr 4, 2012, 207-218.

Bennett, Jill. Empathic Vision. Affect, Trauma, and Contemporary Art. Stanford: Stanford University Press, 2005.

Buci-Glucksmann, Christine. "Eurydice's Becoming-world". W: Art as Compassion: Bracha L. Ettinger, red. Catherine de Zegher, Griselda Pollock. Brussels: ASA Publishers, 2012, 69-88.

Butler, Judith. "Foreword: Bracha's Eurydice”. W: Bracha L. Ettinger, The Matrixial Borderspace, red. Brian Massumi. Minneapolis-London: University of Minnesota Press, 2006, vii-xii.

Chromik, Anna. "Dotyk, rytm i współświadczenie. O afektywnym potencjale materialności i taktylności w twórczości Brachy Ettinger”. Widok. Teorie i Praktyki Kultury Wizualnej, nr 23, 2019, http://www.pismowidok.org/pl/archiwum/2019/23-sila-kobiet/ dotyk-rytm-i-wspolswiadczenie (20.12.2019).

Ettinger, Bracha L. "Fascinance and the Girl-to-m/Other Matrixial Feminine Difference". W: Psychoanalysis and the Image: Transdisciplinary Perspectives, red. Griselda Pollock. Oxford: Blackwell Publishing Ltd., 2006, 60-93.

Ettinger, Bracha L. "Fragilization and Resistance". Studies in the Maternal, t. 1, nr 2, 2009, 1-31, http://www.mamsie.bbk.ac.uk/back_issues/issue_two/documents/Brachal.pdf (16.04.2013).

Ettinger, Bracha L. "Trans-subjective Transferential Borderspace". W: A Shock to Thought: Expression after Deleuze and Guattari, red. Brian Massumi. London-New York: Routledge, 2002, 215-239.

Ettinger, Bracha L. "Weaving a Woman Artist with-in the Matrixial Encounter-Event". W: Bracha L. Ettinger, The Matrixial Borderspace, red. Brian Massumi. Minneapolis-London: University of Minnesota Press, 2006, 173-198.

Ettinger, Bracha L. "Woman-Other-Thing: A Matrixial Touch". W: Matrix - Borderlines. Oxford: Museum of Modern Art, 1993, 11-18.

Kisiel, Anna. “Aesth/ethical Bodies: Bracha Ettinger's Eurydices and the Encounter with the Other's History". W: The Body in History, Culture, and the Arts, red. Justyna Jajszczok, Aleksandra Musiał. New York-London: Routledge, 2019, 149-160.

Kisiel, Anna. “Nie do powiedzenia. O głosie u Lacana, Ettinger i Woodman”. Er(r)go. Teoria - Literatura - Kultura, nr 33, 2/2016, 81-91.

Kisiel, Anna. "Uraz - bliskość - nie-pamięć. Psychoanalityczny dyskurs traumy od Freuda do Ettinger”. Narracje o Zagładzie, nr 2, 2016, 115-132.

Kisiel, Anna. “Touching Trauma: On the Artistic Gesture of Bracha L. Ettinger”. Narracje o Zagładzie, nr 4, 2018, 138-162.

Lévinas, Emmanuel. Całość i nieskończoność. Esej o zewnętrzności, przeł. Małgorzata Kowalska, przekład przejrzał Jacek Migasiński. Warszawa: Wydawnictwo Naukowe PWN, 1998. 
Lévinas, Emmanuel. Ethics and Infinity. Conversations with Philippe Nemo, przel. Richard A. Cohen. Pittsburgh: Duquesne University Press, 1995.

Lévinas, Emmanuel. Inaczej niż być lub ponad istotą, przeł. Piotr Mrówczyński. Warszawa: Fundacja Aletheia, 2000.

Massumi, Brian, "Afterword. Painting: The Voice of the Grain”. W: Bracha L. Ettinger, The Matrixial Borderspace, red. Brian Massumi, Minneapolis-London: University of Minnesota Press, 2006, 201-213.

Pollock, Griselda. “Introduction. Femininity: Aporia or Sexual Difference?”. W: Bracha L. Ettinger, The Matrixial Borderspace, red. Brian Massumi, Minneapolis-London: University of Minnesota Press, 2006, 1-38.

Pollock, Griselda. "Introduction: Trauma and Artworking". W: After-affects / After-images. Trauma and Aesthetic Transformation in the Virtual Feminist Museum. ManchesterNew York: Manchester University Press, 2013, 1-33.

Sontag, Susan. "W platońskiej jaskini”. W: O fotografii, przeł. Sławomir Magala. Warszawa: Wydawnictwa Artystyczne i Filmowe, 1986, 7-28.

Szczepan, Aleksandra. "Krajobrazy postpamięci”. Teksty Drugie, nr 1, 2014, 103-126.

Zelizer, Barbie. Remembering to Forget. Holocaust Memory through the Camera's Eye. Chicago-London: University of Chicago Press, 1998.

Zelizer, Barbie. "Introduction: On Visualizing the Holocaust”. W: Visual Culture and the Holocaust, red. Barbie Zelizer. London: Athlone Press, 2001, 1-10. 